\title{
The Science of Intelligence for Big, Complex Work
}

\author{
doi:10.3991/ijac.v2i2.616 \\ P. N. Gray ${ }^{1}$ and X. Gray ${ }^{2}$ \\ ${ }^{1}$ Charles Sturt University, Bathurst, NSW, Australia \\ ${ }^{2}$ Grays Knowledge Engineering, Sydney, NSW, Australia
}

\begin{abstract}
An epistemological 5GL shell, eGanges, offers systemic intelligence for big, complex work. It is designed for construction of e-learning aids in the workplaces of the finite domains of law, management and education; there may be other suitable uses as well. Law is concerned with large, complex social organisation, and business is concerned with large, complex commercial organisations; work skills for each organisation are taught in tertiary education. This paper illustrates how eGanges aids may be learned in these higher education vocational courses and then, applied seamlessly in the workplace. eGanges applications in the Australian Anti-Money Laundering and Counter-Terrorism Financing Act 2006, and the tasks of a corporate CEO are used to illustrate the nature of the e-Learning and Workplace aids. A major feature of these aids is that they can effect quality control because they permit precise, preplanned micro-management with electronic memory and speed; they are super-agile aids that can be ubiquitous and foster common, comprehensive understanding of large, complex work matters. They show how a science of intelligence supports a leap in the coherence and coordination required for big societies and large work forces.
\end{abstract}

Index Terms-vocational epistemology, androgogy, combinatoric superexpertise, deductive River representation.

\section{INTRODUCTION}

An epistemological 5GL (Fifth Generation Language) shell, eGanges, which was short-listed for the British Computer Society's Machine Intelligence Competition in 2007 at Cambridge University, is designed for construction of e-learning aids for the workplaces of the finite domains of law, management and education. A finite domain is a field of expertise where a finite number of questions and answers are required to resolve a problem.

This paper considers a large scale legal application, and a corporate CEO application that could be used in tertiary teaching of these subjects, as well as in the workplace where such applications might be useful.

A major constituent of 5GL artificial intelligence software is visualisation of intelligence, c.f. [1]; such a representation requires a science of intelligence, which includes a science of choice. In the course of illustrating the sample eGanges applications, the features of the eGanges epistemology are demonstrated as professional logic forms of deduction, induction and abduction that are visible and systemically integrated in the eGanges interface. The eGanges systematization of professional logic is a product of the science of intelligence that contains extended deductive River visualization as the main organising feature that captures choice.

\section{LEGAL APPLICATION - ANTI-MONEY LAUNDERING AND COUNTER-TERRORISM FINANCING}

In 2006, at the height of Jihad terrorism in the world, following the technological destruction of the Twin Towers in New York, the Australian federal government introduced the Anti-Money Laundering and CounterTerrorism Financing Act (AML\&CTF Act). The long title of the AML\&CTF Act is: An Act to combat money laundering and the financing of terrorism, and for other purposes. It is available online at the Australian free law site at [2]. Objects of the Act are set out in section 3, and are primarily concerned with fulfilling Australia's international obligations to combat money laundering and financing of terrorism.

AUSTRAC (Australian Transaction Reports and Analysis Centre; http://www.austrac.gov.au), which was established by the Financial Transaction Reports Act (Cth) 1988 , is continued in existence by, and subject to, the new Act: AML\&CTF Act section 209. Most of the administrative powers of the new legislation are given to the AUSTRAC CEO (Chief Executive Officer). The AUSTRAC CEO has the power to delegate to AUSTRAC staff any or all of the CEO's functions or powers: AML\&CTF Act section 222.

The Act contains simplified outlines in sections 4, 27, $40,52,63,73,80,94,101,104,120,135,144,166,173$, 208, 230 and 234. Other provisions of the Act must be read in accordance with these sections and the objects in section 3 .

AML\&CTF Rules may be made, as subordinate legislation, by the AUSTRAC CEO: AML\&CTF Act section 229. The Governor-General may make Regulations: AML\&CTF Act section 252. The Regulations (2008) are at [3]). The Rules are on the AUSTRAC website at [4]. An amending bill (2007) and its explanatory memoranda can be accessed on the Parliament House website [5].

\section{AUSTRAC MONITORING}

As stated in Note 1, section 3, the objects of the Act are achieved by (among other things) requiring information to be given to the AUSTRAC CEO and allowing access to that information by other agencies. Figure 1 is the Initial eGanges River map of the range of monitoring powers of AUSTRAC. 


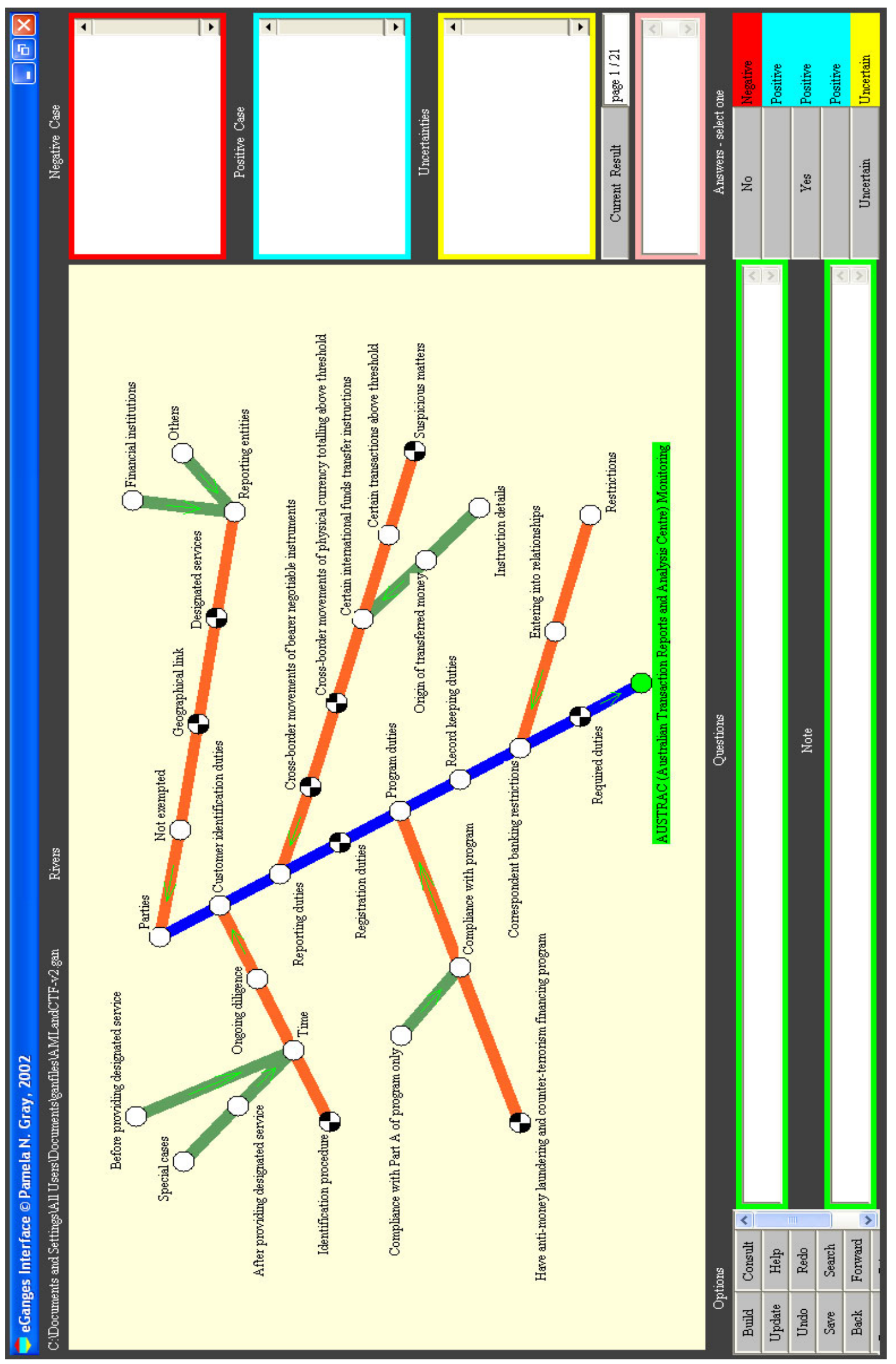

Figure 1. Initial map of AML and CTF Act 2006 (Cth) in eGanges interface (C) Pamela N. Gray, 2008 
The mainstream of the Initial map shows that AUSTRAC monitors the performance by parties defined in the Act (sections 4 and 234), of seven major statutory duties. Relevant sections are as follows:

- Customer identification duty - ss.4, 27 and 234.

- Reporting duty - ss.4, 40, 52, 63 and 234

- Registration duty - ss.4, 73 and 234

- Program duty - ss.4, 80, and 234

- Record keeping duty - ss.104, and 234

- Correspondent banking duty - ss.4, 94, and 234

- Required duty - ss.40, 52, 101, 144, 166, 173 and 234

Note: Where sections (ss.) are given, sometimes the sections following contain details for further consideration.

To examine these seven duties more closely, the relevant sections of the legislation may be read and the eGanges tributaries followed upstream. For instance, the secondary stream that more closely defines Parties sets out the requirements as follows:

1) there must be a reporting entity, further defined in the two alternative tertiary streams as either a financial institution or other reporting entity;

2) there must be designated services (as defined in the sub-map indicated by the node that looks like a soccerball) by the reporting entity. The sub-map of designated services sets out the lists of designated services found in Tables 1-4 of s.6, (now amended by the Regulations (2008)), any one of which will satisfy the requirement that there must be designated services, and all of which define the jurisdiction of AUSTRAC.

3) there must be a geographical link (as defined in the sub-map indicated by the soccerball node) and

4) the reporting entity must not be exempted from compliance with the Act.

A submap of Suspicious matters is shown in Figure 2 which shows that the four antecedents, which constitute a tertiary stream, namely Reportable matter, Reasonable grounds to suspect, Not exempt and Report form requirements must be established in order for Suspicious matters to follow necessarily. Then, in order to establish Reportable matters, the three antecedents of the quaternary stream, namely Occasion, Required condition and At time must be shown. There are four different ways of establishing Occasion each constituted by a single antecedent, for example Inquiry inviting provision of designated service ordinarily provided; there are four single antecedent quinary rules. Finally, the sixth level of tributary defining Inquiry inviting provision of designated service ordinarily provided has two alternate rules. Nesting may be as extensive as the knowledge requires.

The eGanges tributary streams represent formalised rules of law, linked together in a River system. Formalised rules take the structure of conditional propositions: if (antecedent(s)) then consequent. In logic, as premises for deductive reasoning, conditional propositions must have only one consequent. Formal logic has adopted the arrow to represent 'then': $\mathrm{a}, \mathrm{b}, \mathrm{c} \rightarrow \mathrm{d}$. Arrows in the eGanges River are deductive rule arrows and they indicate the direction of flow of arguments or reasoning. In the domain of law, rules of law, established by lawmaking authorities, are then used deductively. If the antecedents required by the rule are shown to exist in a case, then the consequent of the rule necessarily applies. Necessary reasoning is suited to automation.

Sometimes there are choices between rules, such as financial institutions or others as noted in (1) above. Logically, if there is a financial institution, then there is a Reporting entity, OR, if there is a (certain) other, then there is a Reporting entity. Others are further defined in the Act but the application shown has only limited development. As a teaching aid, the limitation is used to set research tasks for students to provide the further detail.

Those who find they have a duty may ascertain the duty requirements by reference to the relevant part of the Initial map, its submaps, and further research specification. Apart from the disjunctions of rules such as for different categories of Reporting entities, all antecedents in the River system must be established to determine all the duties monitored by AUSTRAC. Duties are monitored for each category of Reporting entity.

The AML and CTF application currently has 21 logic maps in its River system; this is incomplete. Figure 3 sets out the remaining maps in a collection which simply indicates the extent of the expert prior analytics that has already been undertaken.

The formalization of maps is a knowledge engineering expertise which was founded by Aristotle as Prior Analytics [6]. Extended deductive reasoning which uses one rule after another, requires both the formalisation of rules and the determination of their relationships to each other i.e. where they overlap primarily in regard to their components of antecedents and consequent. A study of the overlapping is required to formalise the tributaries of their River structure so that the confluence of valid necessary reasoning can be seen plainly in the River map. In the complete picture of the River system, the directional arrows indicate holistically, the available operations of logic flows of specified rule relationships.

Just as some educational posters can show to children the alphabet, and others can show the times tables, as a pedagogy, so River maps can teach extended deduction, and the subject of any such River map. If the subject is an adult subject, such as a job, then the map posters may hang on the wall of the workplace as an androgogical reference during the job performance.

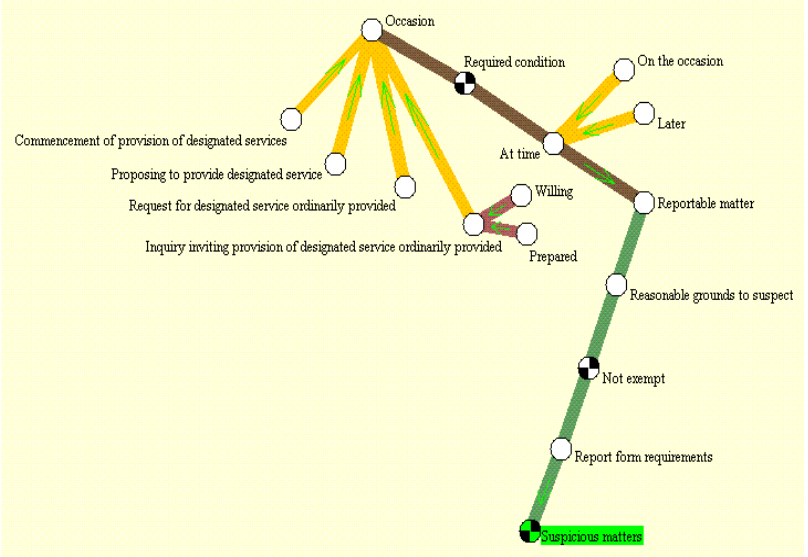

Figure 2. Submap of Suspicious matters of AML \& CTF Act (C) Pamela N. Gray, 2008 


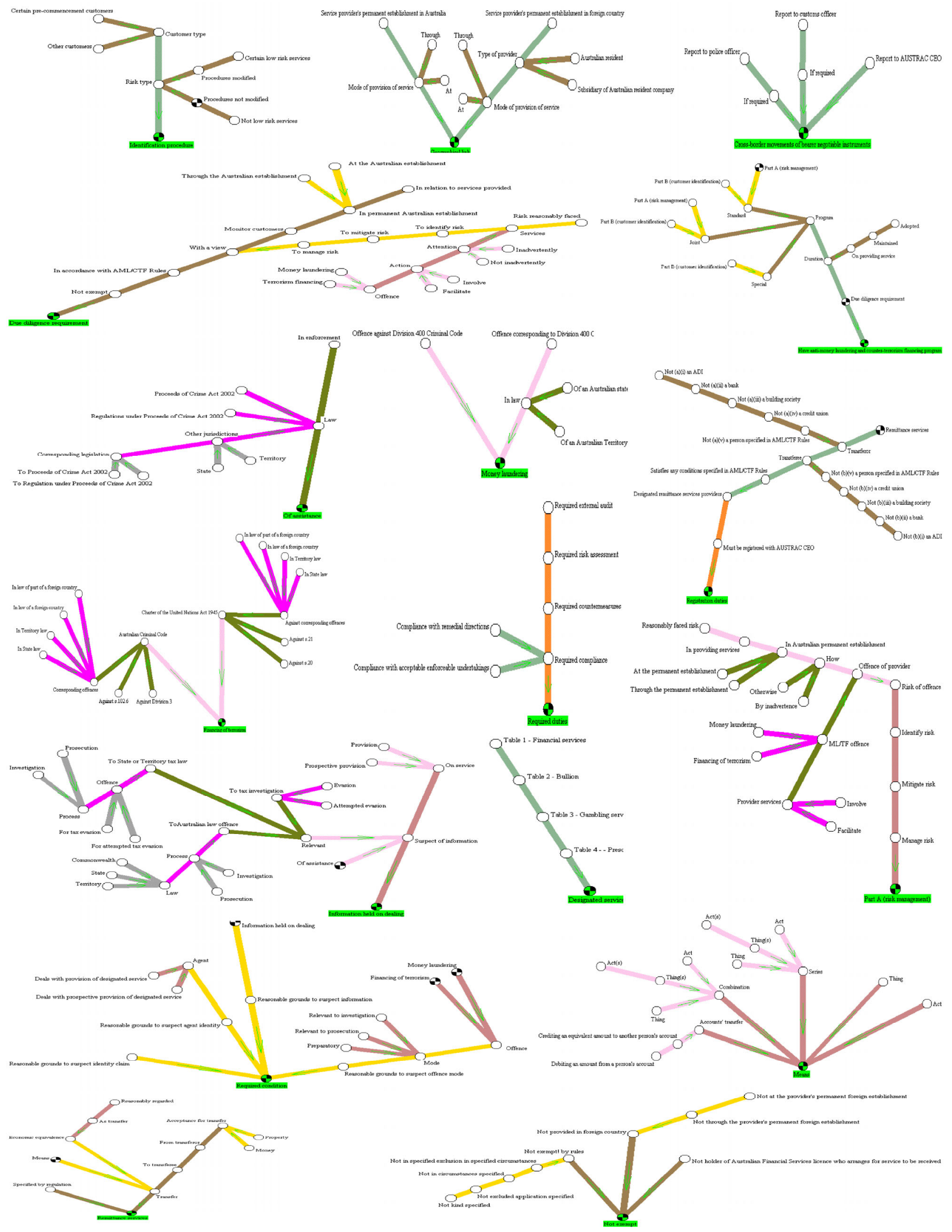

Figure 3. Submap of Suspicious matters of AML \& CTF Act (C) Pamela N. Gray, 2008 
eGanges maps can explain how to spell a word, such as 'was' in terms of phonetics, the position in the alphabet of the letters used, and by distinguishing comparatively differences with other words such as 'mosquito'. Logic structures can be taught in primary school. They may also be used by a corporate CEO. Figure 4 is called the CEO's TV Aerial because that is what it looks like as a mnemonic whole. Yet its mainstream ensures that the CEO will consider environmental and social sustainability in the same frame as production and profit. A comprehensive task is presented for greater consistency and coherence.

There is an eGanges applet available online [7] which maps the Australian corporate law definition of Financial Market; it allows online trial of the extended deductive operations that process the mapping and access to the inductive and abductive premises that gloss nodes.

The operations are determined by combinatorial heuristics that effect the application of the rules to user determined cases or situations. The map can also be seen as the location of related inductive and abductive premises which would otherwise introduce nonmonotonic reasoning to corrupt the necessary validity of extended deduction.

By analogy, if the AML\&CTF mapping or a fully developed CEO quality control River system was processed by eGanges, it can be seen how massive would be the combinatorics which might produce limitations in the monitoring powers of AUSTRAC under the Act that would otherwise be difficult to delineate. Also, the combinatorics might ensure quality controlled compliance with the Act, as it can be ascertained with the speed and accuracy of automation, requiring no deliberation about the necessary reasoning (legal deduction) of the law. Applications which have a different Final result, might require a reconfiguration of the rules in the Act as a River system with that conclusion.

In addition to the applications in law, namely the Australian Anti-Money Laundering and CounterTerrorism Financing Act 2006, which is a large complex legal application, and the Money market definition from the Australian Corporations Act 2001, the use of eGanges aids for quality control management is illustrated by the CEO's TV Aerial.

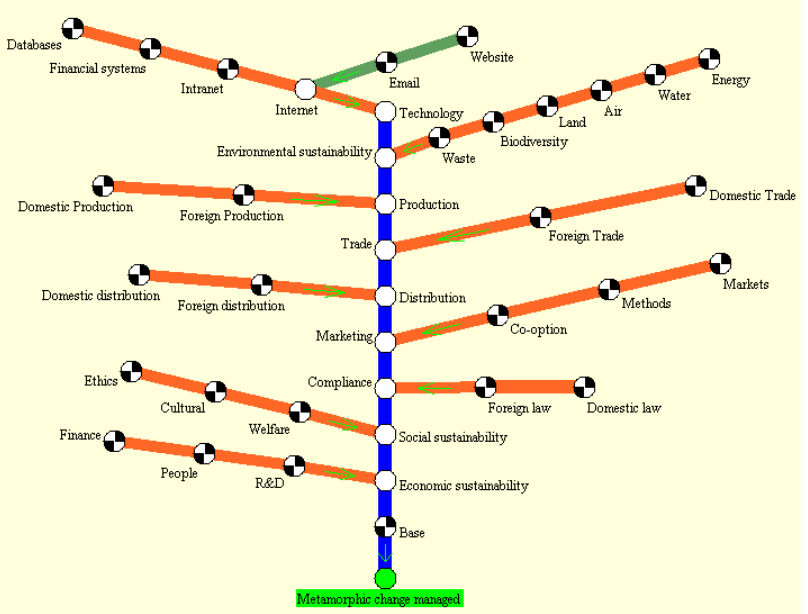

Figure 4. Corporate CEO's TV aerial (C) Pamela N. Gray and Lyn M. Treanor, 2006

\section{SCIENCE OF INTELLIGENCE}

By reference to these samples, the eGanges epistemology, a product of the science of intelligence, can be summarised in terms of what can be seen and what can be seen to be done, as follows:

1) Visualisation of Major deductive premises (conditional propositions or rules) for extended deduction, as a tributary structure called a River system; this is also the structure of Ishikawa [8] quality control fishbones. Rivers have antecedent nodes and consequent nodes, some of which overlap, with inference arrows indicating the directional flow for the extended deduction.

2) Minor premises for extended deduction which are the user input answers to questions in the interface. Each node in the River represents a question which appears in the Questions window, with three possible answers, labelled Negative, Positive and Uncertain; The River node labels for these input answers are returned as listed feedback in the appropriate Case window. Prima facie, a Negative answer is returned in the Negative Case window, a Positive answer is returned in the Positive case window, and an Uncertain answer is returned in the Uncertainties window. All case windows are visible throughout a consultation to display the lists of feedback in each.

3) An interface, minimalised by logic structure; the interface is stable for both construction and consultation of an application. No computer language coding of an application is required. The expert knowledge engineer, through a Build menu, simply constructs the River and adds questions and available answers. Glosses may be created also to annotate any node.

4) Combinatoric heuristics; the range of different answers to the questions allows alternative combinations of answers for the many different questions in a deductive River system. Heuristics are used to process the feedback and the cumulative pro tem and Final results of any user selections.

5) Consistent contradictory premises are accommodated by neutral answers and heuristics; in this case all three possible answers are Positive. Answer buttons are available for this, instead of the choice of Negative, Positive and Uncertain buttons.

6) Consistency disjunction; temporary consequents are used to effect de Morgan's laws of logic that require the contradictory of a conjunction to be a disjunction. To effect this, Negative answers appear, as feedback, initially in the Positive case window, with the addition of (Neg) beside its node label. Then, when the disjunction is exhausted, all labels with (Neg) move to the Negative case window to produce a Negative Final result. A similar heuristic is applied to process Uncertain answers where there is a disjunction;

7) Non-monotonic data in the form of inductive spectra and various abductive premises are located by the 
deductive River map as annotations on antecedent nodes called glosses.

8) Nesting of large complex Rivers as cogart (cognitive art) maps for mnemonics and cognition. Indirect inferencing is automated through the nested structures.

\section{USE OF EGANGES ANDROGOGY}

There are various ways of using eGanges technology in vocational learning and work. Knowledge engineering of the applications itself can be the subject of learning [9][10], Use of the River logic maps may assist teaching and job performance. Experimentation with or use of applications may extend understanding of the combinatoric potential of the real world and its management.

Students who were given a considerable number of maps to support their learning of Business Organisations Law, in 2007, at Charles Sturt University, with little other engagement in the technology, were surveyed for the evaluation of the teaching aids as learning aids. Survey results were mostly favourable.

On the basis of these survey results, further use of the technology in online teaching is planned for 2008 . Already free copies of eGanges have been supplied to students who request one. Student surveys will be conducted to gauge the effect.

It is thought that if knowledge is extensive and complex, intelligent technology aids such as eGanges are needed to manage it for understanding and vocational use. Intelligent technology aids require a science of intelligence for a scientific civilization.

\section{CONCLUSION}

A picture says a thousand words. This saves time and expedites common understanding.

The epistemology of eGanges is expert-friendly for the domains of law, quality control management, and education. It is an extension of the Ishikawa quality control fishbones that were so successful after the second world war in producing high quality Japanese manufacturing.

No coding is required for construction of an application. The interface is minimalistic, according to the logic structure of the epistemology. eGanges is a small program, with a design suited to PDAs and mobile learning [11]. It suggests an androgogy in vocational coursework that permits super-agile job performance in the workplace [12].

The minimalistic language of the eGanges River maps, c.f. [13], and communication system, allows for quick translation to foreign languages. Logic graphics that effectively communicate choice and exact, informed agreement or disagreement introduce a further evolution in human communication and intelligence [14]. Massive agreement becomes possible [15]. People could become proficient in managing human relationships in this way. A major leap toward scientific civilization could result.

The code language of the machine and human language is also reconciled in eGanges through a common visualisation language. While we understand this graphical language, we can enlist machine aids. If we all use the same machine aids, human intelligence is extended by artificial intelligence.

eGanges does require the deconstruction and reconstruction of human language through analytics prior to construction of an application. Aristotle's Prior Analytics [6] applies in knowledge engineering so that the benefits of electronic memory and processing speed can contribute to the development of human culture.

e-learning in the workplace, with eGanges application aids, is likely to increase available human intelligence and its use so that people can move more fully into the age of science, with greater understanding and safety. Science precision jobs are facilitated. The twilight world of the $20^{\text {th }}$ century, when the discoveries of science were used by quasi-rational people, produced serious risks to human survival. Intelligent technology aids that make higher intelligence easy, now offer a way to pass through this period of risk to a new level of higher education and social evolution.

The mind tools developed during the post-modern period in the second half of the twentieth century, may have provided the means for creation of an advanced age of scientific civilization, with a common new graphical language of logic for the informed negotiation of social and commercial organisation of human survival.

\section{REFERENCES}

[1] Orna, E. (2005): Making Knowledge Visible, Gower, Aldershot, England

[2] http://www.austlii.edu.au/au/legis/cth/bill_em/alacfab2007612/me mo $0 . h t m l$

[3] http://www.austlii.edu.au/au/legis/cth/consol_act/alacfa2006522/

[4] http://www.austlii.edu.au/au/legis/cth/num_reg/alacfr2008n20200 8714.txt/cgi-bin/download.cgi/download/au/legis/cth/num_reg/ alacfr2008n2o2008714.rtf

[5] http://www.austrac.gov.au/aml ctf rules.html

[6] Aristotle (1952, originally c.335 BC): Organon, in R. M. Hutchins (ed.) Great Books of the Western World, Vol 8, Encyclopaedia Britannica Inc., Chicago, USA.

[7] http://www.grayske.com/FinLawTrial/index.html

[8] Ishikawa, K. (1985): What is total quality control? The Japanese way, translated by David J. Lu., PrenticeHall Inc., Englewood Cliffs, N.J., USA.

[9] Gray, P.N. (2007): Legal Knowledge Engineering Methodology for Large Scale Expert Systems, PhD thesis, University of Western Sydney, Australia: http://library.uws.edu.au/public/adt-NUWS20 071010.121246/index.html

[10] Gray, P.N. (1997): Artificial Legal Intelligence, Dartmouth, Aldershot, England

[11] Gray, P.N., Gray, X. and Treanor, L.M. (2006): Handheld intelligence for contemporary free trade, in Proceedings of third International Conference on Contemporary Business (CD), Charles Sturt University

[12] Gray, P.N., Gray, X. and Treanor, L.M. (2007): Clues, Cues, Combinatorics and Super-agile Management Androgogy, in Proceedings of the International Business Research Conference, University of Technology, Sydney

[13] Ong, W.J. (1958): Ramus Method and the Decay of Dialogue, Harvard University Press, Cambridge, MA, U.S.A.

[14] Gray, P.N., Gray, X. and Zeleznikow, J. (2007): Negotiating Logic: For richer or poorer in Proceedings of the International Conference on Artificial Intelligence and Law, Stanford University, ACM

[15] Gray, P.N., Tierney, R., Gray, X. and Treanor, L.M. (2006): eGanges: Pervasive Peacemaker, in Proceedings of The First International Symposium on Pervasive Computing and Applications, Urumchi China, IEEE. 


\section{AUTHORS}

P. N. Gray is with the Centre for Research in Complex Systems, Charles Sturt University, Bathurst, NSW, Australia

X. Gray is with Grays Knowledge Engineering, Sydney, NSW, Australia

Manuscript received 14 July 2008. Published as submitted by the authors. 